\title{
Métodos de quantificação da cobertura foliar da infestação de plantas daninhas e da cultura da soja ${ }^{1}$
}

\author{
Methods of quantification of weeds and soybean leaf covers ${ }^{1}$
}

\author{
Mauro Antônio Rizzardi ${ }^{2}$ Nilson Gilberto Fleck ${ }^{3}$
}

\section{RESUMO}

A utilização de modelos matemáticos para previsão de perdas de rendimento de grãos causadas pela infestação das plantas daninhas, que usam a medida da área foliar, depende da rapidez e precisão da estimativa dessa variável. Neste sentido, a cobertura foliar, definida como a proporção de área do solo ocupada pela projeção vertical da parte aérea de uma espécie, pode ser uma alternativa viável. $O$ objetivo deste trabalho foi comparar a eficiência de métodos de avaliação da estimativa da cobertura foliar relativa na quantificação das perdas de rendimento de grãos de soja causadas por Bidens spp. (picão-preto) ou Sida rhombifolia L. (granxuma). Foram conduzidos experimentos em campo, utilizando-se diferentes épocas de semeadura da cultura da soja em relação à dessecação da cobertura vegetal da área, e densidades variáveis de picão-preto ou guanxuma. Avaliaram-se as coberturas foliares das plantas daninhas e da cultura aos 20 dias após a emergência da soja. Constatouse que métodos fotográficos de avaliação da cobertura foliar, integrados a auxílios computacionais, são alternativas promissoras na quantificação dessa variável, embora a avaliação visual seja mais prática e rápida de ser determinada.

Palavras-chave: Bidens spp., Sida rhombifolia L., cobertura do solo, previsão de perdas.

\section{ABSTRACT}

The utilization of mathematical models in order to predict grain yield losses due to weed infestations, which use leaf area measures, depends on the rapid and precise evaluation of this variable. This way, leaf cover, defined as the proportion of soil area accupied by the vertical projection of the foliage of a species, can be a viable alternative. The purpose of this research was to compare the efficiency of methods to evaluate leaf cover in quantifying soybean grain yield losses due to Bidens spp. (beggarticks) and Sida rhombifolia L. (arrowleaf sida). Weeds and crop leaf covers were evaluated 20 days after soybean emergency. It was proved that photographic methods of evaluating leaf cover, integrated to computing aids, are promising alternatives in quantifying this variable although visual evaluation was more practical and rapid to be performed.

Key words: Bidens spp., Sida rhombifolia L., soil cover, yield loss prediction.

\section{INTRODUÇÃO}

A cultura da soja é estabelecida em condições de ambientes e de sistemas tecnológicos diversos, o que acarreta a obtenção de níveis variáveis de produtividade entre as regiões produtoras. Essas produtividades, principalmente no Rio Grande do Sul, estão bem abaixo do potencial da cultura e, também, dos rendimentos obtidos por agricultores que utilizam altos níveis de tecnologia. Entre as causas da baixa produtividade da cultura destaca-se a presença de plantas daninhas infestando as lavouras. Os efeitos negativos da sua presença em lavouras de soja incluem a competição que exercem por recursos limitados de crescimento, aumento do custo de produção, dificuldade de colheita, depreciação da qualidade do produto, hospedagem de pragas e doenças e diminuição do valor comercial das áreas cultivadas (MARRA \& CARLSON, 1983).

As infestações de plantas daninhas em cultivos em fileiras normalmente são quantificadas pela

\footnotetext{
${ }^{1}$ Parte da tese do primeiro autor para a obtenção do título de doutor em Fitotecnia.

${ }^{2}$ Engenheiro Agrônomo, Mestre, Professor da Faculdade de Agronomia e Medicina Veterinária da Universidade de Passo Fundo (UPF) e aluno do Programa de Pós-graduação em Fitotecnia da Universidade Federal do Rio Grande do Sul (UFRGS). CP 611, 99001-970, Passo Fundo, RS. E-mail:rizzardi@upf.tche.br. Autor para correspondência.

${ }^{3}$ Engenheiro Agrônomo, Ph.D., Professor do Departamento de Plantas de Lavoura da Faculdade de Agronomia, UFRGS.
} 
contagem de amostras do número de indivíduos presentes na área. O conhecimento da intensidade da infestação e da forma como essa pode ser usada para descrever as perdas de rendimento é fundamental para adoção antecipada de medidas de controle de plantas daninhas (COUSENS, 1985). Esse procedimento, além de ser demorado e cansativo, somente pode ser usado como previsor adequado da competição quando a emergência das populações de plantas daninhas é uniforme e concentrada no tempo (VITTA et al., 1993). Uma das questões mais importantes na estimativa da infestação de plantas daninhas é dispor-se de métodos que quantifiquem sua presença e distribuição de forma rápida e econômica. No momento, parece não haver outra possibilidade realística do que mapear as plantas daninhas através de observações sistemáticas da lavoura.

Pesquisas mostram haver uma estreita relação entre perda de rendimento e cobertura do solo propiciado pelo dossel das plantas daninhas e da cultura, medida pouco após a emergência da cultura (KROPFF \& SPITTERS, 1991). O modelo da cobertura foliar relativa estima o efeito de densidades e fluxos de emergência de plantas daninhas, constituindo-se em medida precisa que substitui outros métodos de quantificação da infestação de plantas daninhas, como densidade de plantas e área foliar relativa (KROPFF \& SPITTERS, 1991; KROPFF \& LOTZ, 1992). Para BERTI \& SATTIN (1996), o uso da cobertura foliar relativa diminui a variabilidade entre anos na estimativa das perdas de rendimento de grãos da cultura causadas pela presença de plantas daninhas. Segundo os autores, isso ocorre porque a cobertura foliar relativa contempla, indiretamente, tanto a época de emergência quanto a localização espacial das plantas daninhas.

Apesar desses resultados positivos, DIELEMAN et al. (1995) não observaram melhorias no ajuste do modelo testado pela inclusão da porcentagem de cobertura. Segundo BERTI \& ZANIN (1997), no momento em que a infestação deve ser avaliada, a cobertura do solo pelas plantas daninhas é muito baixa e os erros cometidos na estimativa, usando esta variável, podem ser grandes. Assim, as limitações na utilização da variável cobertura foliar podem estar associadas aos procedimentos adotados para sua avaliação. Neste sentido, diferentes autores salientam que um problema não resolvido no uso da variável cobertura foliar refere-se à disponibilidade de um método confiável, rápido e barato de estimativa no início do crescimento das plantas daninhas, quando a tomada de decisão deve ser definida (KROPFF \& SPITTERS, 1991; BERTI \& SATTIN, 1996). Diante disso, objetivou-se, com este trabalho, comparar a eficiência de métodos de avaliação da cobertura foliar relativa do solo com plantas daninhas na quantificação das perdas de rendimento de grãos de soja.

\section{MATERIALEMÉTODOS}

Os experimentos foram conduzidos em campo, durante a estação de crescimento 1999/00, na Estação Experimental Agronômica da Universidade Federal do Rio Grande do Sul (EEA/UFRGS), localizada no Município de Eldorado do Sul - RS, região fisiográfica da Depressão Central do Estado. O solo da área experimental é classificado como Argissolo Vermelho Distrófico típico (EMBRAPA, 1999).

O delineamento experimental utilizado nos experimentos foi completamente casualizado, com os tratamentos dispostos em esquema fatorial, sem repetições. Os tratamentos representativos do fator $\mathrm{A}$ constaram de densidades de picão-preto (Bidens pilosa L. e B. sulbalternans DC., em infestações mistas) ou de guanxuma (Sida rhombifolia L.), e os do fator B de épocas de semeadura da soja em relação à data de dessecação da cobertura vegetal existente na área. A semeadura da soja foi realizada 3, 7 e 11 dias após dessecação (DAD) no experimento com picãopreto, e aos 20, 24 e 28 DAD para o de guanxuma. Foi conduzido um terceiro experimento, também em delineamento completamente casualizado, sem repetições, que foi estabelecido em uma só época de semeadura da soja, aos 20 DAD.

As densidades de plantas daninhas foram alocadas aleatoriamente no campo, de acordo com níveis populacionais encontrados naturalmente nas áreas. Para picão-preto utilizaram-se 10 unidades em cada época de semeadura, cujas densidades variaram de uma a 110 plantas $\mathrm{m}^{-2}$, totalizando 30 unidades com infestação; para guanxuma, utilizaram-se 10 unidades em cada época, com densidades que variaram de uma a 128 plantas $\mathrm{m}^{-2}$, perfazendo o total de 30 unidades com infestação. No experimento sem o fator épocas de semeadura, utilizaram-se 15 unidades com infestação de picão-preto, com densidades da planta daninha variáveis de três a 176 plantas $\mathrm{m}^{-2}$. Em todos os experimentos, mantiveram-se quatro a cinco unidades com ausência de plantas daninhas, em cada uma das épocas de semeadura da soja. Cada unidade experimental mediu $6 \mathrm{~m}^{2}(2 \mathrm{~m} \times 3 \mathrm{~m})$, constando de cinco fileiras de soja espaçadas em $0,4 \mathrm{~m}$.

Os experimentos foram implantados utilizando-se o sistema de semeadura direta, sem preparo mecânico do solo, em áreas contendo cobertura vegetal composta por aveia-preta (Avena strigosa Schreb) e algumas espécies daninhas. O 
manejo da cobertura foi realizado através da aplicação da mistura dos herbicidas glyphosate (900g de equivalente ácido ha $\left.{ }^{-1}\right)$ e 2,4-D (670g de equivalente ácido ha $^{-1}$ ), efetuada por ocasião do florescimento das plantas de aveia-preta. No experimento conduzido com picão-preto, foi procedida uma segunda dessecação com o herbicida paraquat $\left(300 \mathrm{~g} \mathrm{ha}^{-1}\right), 3$ dias antes da primeira época de semeadura da soja, para eliminar as plantas daninhas que não foram controladas com a primeira dessecação e, também, plantas daninhas que emergiram no período entre a primeira e a segunda dessecação. Para guanxuma, foi realizada somente uma dessecação, 20 dias antes da primeira época de semeadura da soja. Para o experimento com picãopreto, sem diferimento de épocas de semeadura da soja, foi realizada apenas uma dessecação, 20 dias antes da semeadura da soja.

A adubação do solo foi realizada através da distribuição de $17 \mathrm{~kg}$ de $\mathrm{N} \mathrm{ha}^{-1}, 85 \mathrm{~kg}$ de $\mathrm{P}_{2} \mathrm{O}_{5}$ ha $^{-1} \mathrm{e}$ $85 \mathrm{~kg}$ de $\mathrm{K}_{2} \mathrm{O}$ ha $^{-1}$. Antecedendo a semeadura, as sementes de soja foram inoculadas com estirpes de Bradyrhizobium japonicum (SEMIA 5019) e foram tratadas com o fungicida thiram $\left(70 \mathrm{~g} 100 \mathrm{~kg}^{-1} \mathrm{de}\right.$ sementes).

Em ambos os experimentos, utilizou-se a cultivar de soja Embrapa 66, de ciclo médio de desenvolvimento e estatura média $(83 \mathrm{~cm})$ a qual foi estabelecida na densidade de 400 mil plantas ha-1. A semeadura da cultura deu-se em 17, 21 e 25 de novembro de 1999, no experimento com guanxuma; e, em 8, 12 e 16 de dezembro, para o experimento com picão-preto. No experimento de picão-preto em que não foram implantadas épocas de semeadura da soja, realizou-se a semeadura em 08 de novembro de 1999.

O controle de plantas daninhas gramíneas nos experimentos foi obtido mediante aplicação do herbicida graminicida clethodim $\left(120 \mathrm{~g} \mathrm{ha}^{-1}\right)$, acrescido do adjuvante Assist usado a 0,5\% volume/volume, quando as plantas daninhas apresentavam duas folhas desenvolvidas. A aplicação do herbicida foi realizada com pulverizador costal de precisão, operado com bicos de jato plano, em leque, série 110.03 , à pressão constante de $200 \mathrm{kPa}$, distribuindo volume de calda equivalente a $200 \mathrm{~L} \mathrm{ha}^{-1}$. As demais plantas daninhas dicotiledôneas foram retiradas manualmente da área. Durante a condução dos experimentos, foram realizadas suplementações hídricas por meio de irrigações por aspersão, a fim de se garantir adequado desenvolvimento à cultura.

A cobertura foliar do solo por plantas daninhas e cultura foi avaliada de forma visual, mecânica e ótica, aos 20 dias após a emergência (DAE) da cultura, quando as plantas de soja apresentavam 3 trifólios e as plantas daninhas 2 folhas desenvolvidas. A avaliação visual foi realizada utilizando-se escala percentual, em que nota zero correspondeu à ausência de cobertura vegetal do solo e nota 100 significou cobertura completa do solo. A avaliação mecânica foi realizada através da projeção vertical de agulhas (método do ponto quadrado). Em cada unidade experimental, foi posicionado um quadrado com $2,0 \mathrm{~m}$ de lado e 1,0m de altura, contendo duas barras dispostas nas diagonais opostas. Nas barras, foram fixadas agulhas de ferro que se prolongavam até tocarem o solo, totalizando 12 pontos por diagonal, totalizando 24 pontos por parcela. Para cada unidade, verificava-se o número de contatos das agulhas com folhas de plantas daninhas ou de soja. Caso ocorresse contato foliar nos 24 pontos amostrados, a cobertura do solo proporcionada por plantas da planta daninha ou da cultura representava $100 \%$.

Para avaliação ótica foram tiradas fotografias em duas áreas de $0,5 \mathrm{~m}^{2}$ por unidade experimental, utilizando-se a máquina marca Yashica, modelo FX-D quartz. Nas fotos, inicialmente, a avaliação da cobertura consistiu na utilização de uma grade quadriculada com 24 pontos marcados em lâmina plástica (transparência), a qual era superposta às fotos e anotado o número de interseções (pontos) que se sobrepunham às folhas das plantas. Uma segunda forma de avaliação consistiu da projeção das fotos com auxílio do aplicativo computacional Power Point. Com esse método, a cada projeção foi superposta uma grade quadriculada totalizando 50 ou 180 pontos. Tanto no primeiro quanto no segundo procedimento, estimou-se o número de vezes em que se visualizava contato de pontos com folhas das plantas daninhas ou da cultura, sendo que o número de coincidências era convertido em porcentagem em relação ao total de pontos em cada situação. A avaliação ótica da cobertura foi realizada com auxílio do programa computacional Adobe PhotoDeluxe 2.0 no qual, inicialmente, as fotos foram digitalizadas para permitir a identificação e diferenciação das plantas das plantas daninhas alvo e da cultura. Posteriormente, foi calculada a participação de cada espécie em relação à área total de solo amostrada, contida na foto, com auxílio do programa Sigma Scan.

A contribuição relativa da cobertura foliar das plantas daninhas foi calculada de acordo com a Equação 1, proposta por VITTA \& FERNANDEZ QUINTANILLA(1996).

$$
\left.\mathrm{C}_{\mathrm{fr}}=\left(\mathrm{C}_{\mathrm{f}}\right) /\left(\mathrm{C}_{\mathrm{fe}}+\mathrm{C}_{\mathrm{fc}}\right) \quad \text { (Equação } 1\right)
$$

onde: $\mathrm{C}_{\mathrm{fr}}^{\mathrm{e}}=$ cobertura foliar relativa; $\mathrm{C}_{\mathrm{fe}}=$ cobertura foliar da planta daninha $\mathrm{m}^{-2} ; \mathrm{C}_{\mathrm{fc}}=$ cobertura foliar da cultura $\mathrm{m}^{-2}$. 
O rendimento de grãos de soja foi determinado em área de $3,0 \mathrm{~m}^{2}(1,2 \mathrm{~m} \times 2,5 \mathrm{~m})$, englobando as três fileiras centrais das parcelas. Por ocasião da pesagem dos grãos foi determinada sua umidade e, posteriormente, os pesos obtidos foram uniformizados para $13 \%$ de umidade. Aos dados de rendimento, foram calculadas as perdas percentuais em relação às parcelas testemunhas mantidas livres de plantas daninhas.

Aos dados de porcentagem de perda de produtividade, foi ajustado modelo de regressão não linear, com base na hipérbole retangular, conforme foi proposto por LOTZ et al. (1996):

(Equação 2)

$$
\mathrm{P}_{\mathrm{r}}=(100 * \mathrm{q} * \mathrm{C}) /(1+((\mathrm{q} / \mathrm{m})-1) * \mathrm{C})
$$

onde: $\mathrm{P}_{\mathrm{r}}=$ perda de rendimento $(\%) ; \mathrm{C}=$ cobertura foliar relativa; $\mathrm{q}=$ coeficiente de dano relativo, estimado pelo modelo; $\mathrm{e}, \mathrm{m}=$ perda máxima de rendimento, estimada pelo modelo.

Os ajustes do modelo da equação 2 aos dados foram realizados usando-se o procedimento Proc Nlin do programa computacional SAS (SAS, 1989). O modelo da equação 2 foi ajustado individualmente para as variáveis explicativas para cada época de semeadura da soja. Após o ajuste do modelo, fez-se comparação dos modelos ajustados entre épocas, procedendo-se inicialmente a verificação de homogeneidade de variância pelo teste de Bartlett (Gomez \& Gomez, 1984). Nos casos em que houve homocedasticidade, foi realizada a comparação entre épocas, conforme Chow (Florez et al., 1999). A escolha do melhor método de avaliação da cobertura foliar baseou-se na combinação do maior valor de $\mathrm{R}^{2}$ e do menor valor de soma de quadrados do resíduo (SQR). Na comparação dos métodos de avaliação da cobertura foliar, além da análise de regressão, procedeu-se, adicionalmente, análise de correlação linear simples dos métodos com as perdas de rendimento de grãos.

\section{RESULTADOS E DISCUSSÃO}

Na comparação dos métodos de avaliação de cobertura foliar (Tabela 1), deduz-se, para picãopreto, que os melhores ajustes foram obtidos através do método fotográfico $\left(R^{2}=0,68\right)$, que consistiu na sobreposição de grade quadriculada às fotos projetadas, com 180 pontos de leitura. Os melhores ajustes obtidos por esse método podem ser explicados pelo número significativamente maior de pontos utilizados, o que melhorou bastante a precisão de

Tabela 1 - Comparação entre métodos de estimativa da cobertura foliar relativa por picão-preto e guanxuma na cultura da soja, Eldorado do Sul - RS, 1999/00

\begin{tabular}{|c|c|c|c|c|}
\hline Métodos de avaliação & $\mathrm{q}^{2}$ & $\mathrm{~m}^{3}$ & Soma dos quadrados dos resíduos & $\begin{array}{c}\text { Coeficiente de } \\
\text { determinação }\left(\mathrm{R}^{2}\right)\end{array}$ \\
\hline & & & Picão-preto & \\
\hline Visual $^{4}$ & 2,30 & 38,6 & 1658 & $0,59 *$ \\
\hline Ponto quadrado ${ }^{5}$ & 1,30 & 47,7 & 2154 & $0,47 *$ \\
\hline \multicolumn{5}{|l|}{ Fotográfico $^{6}$} \\
\hline Método 1 & 8,65 & 44,0 & 2348 & $0,42 *$ \\
\hline Método 2 & 3,34 & 42,9 & 2123 & $0,48^{*}$ \\
\hline \multirow[t]{2}{*}{ Método 3} & 8,06 & 42,5 & 1303 & $0,68 *$ \\
\hline & & & Guanxuma & \\
\hline Visual $^{4}$ & 2,29 & 51,0 & 4562 & $0,56^{*}$ \\
\hline Ponto quadrado ${ }^{4}$ & 1,18 & 64,8 & 4624 & $0,55^{*}$ \\
\hline \multicolumn{5}{|l|}{ Fotográfico $^{6}$} \\
\hline Método 1 & 6,28 & 51,5 & 4703 & $0,55^{*}$ \\
\hline Método 4 & 6,05 & 69,8 & 3225 & $0,69 *$ \\
\hline
\end{tabular}

${ }^{1}$ Estimados pela equação $\mathrm{P}_{\mathrm{r}}=(100 * \mathrm{q} * \mathrm{C}) /(1+((\mathrm{q} / \mathrm{m})-1) * \mathrm{C})$; onde: $\mathrm{P}_{\mathrm{r}}=$ perda de rendimento; $\mathrm{C}=$ cobertura foliar relativa.

${ }^{2}$ Coeficiente de dano relativo, estimado pelo modelo de regressão.

${ }^{3}$ Perda máxima de rendimento da cultura, estimada pelo modelo de regressão.

${ }^{4}$ Avaliado utilizando escala percentual.

${ }^{5}$ Avaliado mediante a projeção vertical de 6 agulhas $\mathrm{m}^{-2}$

${ }^{6}$ Os métodos representam: 1 = superposição de grade quadriculada às fotografias de campo; 2 e 3 = projeções de fotos no aplicativo computacional Power Point e superposição de grades quadriculadas, com 50 e 180 pontos, respectivamente; $4=$ digitalização das fotos em computador e avaliação no programa Sigma Scan .

* Indica significância a 5\% de probabilidade. 
estimativa em baixas densidades de plantas daninhas; porém, mostrou-se um método trabalhoso e demorado, devido ao elevado número de pontos que envolveu. A estimativa precisa da cobertura foliar em baixas densidades de plantas daninhas é uma das principais limitações aos métodos fotográficos e, principalmente, ao método do ponto quadrado. Um método de avaliação que se mostrou viável para superar a limitação de estimar coberturas em baixas densidades foi o visual; no entanto, o ajuste propiciado por esse método foi inferior ao método fotográfico com 180 pontos (Tabela 1).

Para guanxuma, o método fotográfico de avaliação da cobertura que utilizou digitalização das fotos foi o que proporcionou o melhor ajuste (Tabela 1). Por esse método, foi possível diferenciar e quantificar as populações de plantas daninhas e cultura, bem como estimar a área de solo teoricamente coberta pelas mesmas. Porém, no momento ainda é uma avaliação muito demorada, pois a diferenciação das plantas de ervas e culturas é difícil de ser obtida e quantificada simultaneamente. Além disso, é um método que requer conhecimento de informática e equipamento computacional que, em geral, ainda não fazem parte do cotidiano da maioria dos agricultores.

Os coeficientes de correlação linear entre os métodos de avaliação da cobertura foliar relativa e perdas de rendimento da soja variaram de 0,66 a 0,72 para picãopreto e de 0,73 a 0,80 para guanxuma (Tabela 2). Ressaltese que houve resposta similar nas associações obtidas quando da comparação entre espécies para um mesmo método de avaliação da cobertura foliar.

A utilização da cobertura foliar relativa como variável independente, na predição das perdas de rendimento causadas por plantas daninhas, justifica-se caso houver disponibilidade de métodos rápidos e precisos para sua determinação. Neste sentido, a cobertura foliar relativa avaliada visualmente, apesar de apresentar ajuste inferior a alguns métodos fotográficos disponíveis (Tabela 1), possui vantagens, como rapidez de execução e capacidade de distinguir infestações muito baixas de plantas daninhas. Neste contexto, VITTA \& FERNANDEZ QUINTANILLA (1996) testaram um método de dispositivo ótico que desenvolveram para predizer o resultado da competição plantas daninhas:cultura; no entanto, o método visual ainda apresentou superioridade. Eles ressaltam que a superioridade apresentada por modelos de cobertura de plantas daninhas baseados em estimativas visuais deve-se à habilidade de se distinguir visualmente níveis muito baixos de área foliar das plantas daninhas. Medições da cobertura de plantas daninhas em infestações muitos baixas são cruciais, caso devam determinar-se níveis de dano econômico. Em tais circunstâncias, estimativas visuais seriam especialmente convenientes, devido à habilidade em distinguir níveis muito baixos de área foliar das plantas daninhas. Quando a espécie daninha for altamente competitiva, o nível de dano econômico provavelmente seja alcançado com infestação de plantas daninhas bastante baixa (VITTA \& FERNANDEZ QUINTANILLA, 1996).

A principal restrição à avaliação visual consiste na subjetividade do avaliador (NGOUAJIO et al., 1998; NGOUAJIO et al., 1999). A experiência do observador ou características da espécie (cor, forma de crescimento) podem influenciar consideravelmente os dados (LOTZ et al., 1994). Sob condições de baixos níveis de infestação de plantas daninhas, as estimativas visuais claramente superestimam os valores de área foliar (VITTA \& FERNANDEZ QUINTANILLA, 1996). Experimentos demonstraram que o método visual estima a área foliar com parcialidade, e que para superar este viés, tal parcialidade deveria ser mantida constante em todas as avaliações. Em conseqüência, são necessários observadores treinados para que o método possa ser confiável quando utilizado em sistemas de manejo de plantas daninhas (VITTA \& FERNANDEZ QUINTANILLA, 1996).

Tabela 2 - Coeficientes de correlação linear simples entre métodos de avaliação da cobertura foliar relativa e perdas de rendimento de grãos de soja causadas por infestações de picão-preto ou guanxuma, Eldorado do Sul - RS, 1999/00

\begin{tabular}{lcc}
\hline \multirow{2}{*}{$\begin{array}{l}\text { Métodos de avaliação } \\
\text { da cobertura foliar }\end{array}$} & \multicolumn{2}{c}{ Coeficientes de correlação (R) } \\
\cline { 2 - 3 } & Picão-preto & Guanxuma \\
\hline Visual $^{1}$ & $0,72^{*}$ & $0,73^{*}$ \\
Ponto quadrado $^{2}$ & $0,73^{*}$ & $0,75^{*}$ \\
Fotográfico $^{3}$ & & \\
Método 1 & $0,70^{*}$ & $0,73^{*}$ \\
Método 2 & $0,63^{*}$ & $* *$ \\
Método 3 & $0,66^{*}$ & $* *$ \\
Método 4 & $* *$ & $0,80^{*}$ \\
\hline
\end{tabular}

${ }^{1}$ Avaliado utilizando escala percentual.

${ }^{2}$ Avaliado mediante a projeção vertical de 6 agulhas $\mathrm{m}^{-2}$.

Os métodos representam: $1=$ superposição de grade quadriculada às fotografias de campo; 2 e 3 = projeções das fotos no aplicativo computacional Power Point e superposição de grades quadriculadas, com 50 e 180 pontos, respectivamente; 4 = digitalização das fotos em computador e avaliação no programa Sigma Scan.

Valores significativos a $5 \%$ de probabilidade.

** Método não avaliado.

Ciência Rural, v. 34, n. 1, jan-fev, 2004. 


\section{CONCLUSÕES}

Dentre os métodos de quantificação da cobertura foliar através de amostragens, a digitalização de fotografias em programas computacionais mostra perspectiva promissora de utilização como variável explicativa na previsão de perdas de rendimento de grãos de soja por guanxuma e picão-preto.

O método de quantificação visual da cobertura foliar, embora sem resultar no melhor ajuste dentre as variáveis estudadas, apresenta vantagens de ordem prática em relação às outras técnicas testadas.

\section{REFERÊNCIAS BIBLIOGRÁFICAS}

BERTI, A.; SATIN, M. Effect of weed position on yield loss in soyabean and a comparison between relative weed cover and other regression models. Weed Research, Oxford, v.36, n.3, p.249-258, 1996.

BERTI, A.; ZANIN, G. Gestinf: a decision model for postemergence weed management in soybean [Glycine max (L.) Merr.]. Crop Protection, Surrey, v.16, n.2, p.109-116, 1997.

COUSENS, R. An empirical model relating crop yield to weed and crop density and a statistical comparison with other models. Journal of Agricultural Sciences, Cambridge, v.105, n.3, p.513-521, 1985.

DIELEMAN, A. et al. Empirical models of pigweed (Amaranthus spp.) interference in soybean (Glycine max). Weed Science, Champaign, v.43, n.4, p.612-618, 1995.

EMBRAPA. Centro Nacional de Pesquisa de Solos. Sistema brasileiro de classificação de solos. Brasília : EMBRAPA, 1999. 412p.

FLOREZ et al. Predicting rice yield losses caused by multispecies weed competition. Agronomy Journal, Madison, v.91, n.1, p.87-92, 1999.
GOMEZ, K.A.; GOMEZ, A.A. Statistical procedures for agricultural research. 2.ed. New York : Willey, 1984. 680p.

KROPFF, M.J.; LOTZ, L.A.P. Optimization of weed management systems: the role of ecological models of interplant competition. Weed Technology, Champaign, v.6, n.2, p.462-470, 1992 .

KROPFF, M.J.; SPITTERS, J.T. A simple model of crop loss by weed competition from early observations on relative leaf area of the weeds. Weed Research, Oxford, v.31, n.2, p.97$105,1991$.

LOTZ, L.A.P. et al. Prediction of the competitive effects of weeds on crop yields based on the relative leaf area of weeds. Weed Research, Oxford, v.36, n.1, p.93-101, 1996.

LOTZ, L.A.P. et al. Techniques to estimate relative leaf area and cover of weeds in crops for yield loss prediction. Weed Research, Oxford, v.34, n.3, p.167-175, 1994.

MARRA, M.C.; CARLSON, G.A. An economic threshold model for weeds in soybeans (Glycine max). Weed Science, Champaign, v.31, n.5, p.604-609, 1983.

NGOUAJIO, M. et al. Validation of an operator-assisted module to measure weed and crop leaf cover by digital image analysis. Weed Technology, Lawrence, v.12, n.3, p.446453, 1998.

NGOUAJIO, M.; LEMIEUX, C.; LEROUX, G.D. Prediction of corn (Zea mays) yield loss from early observations of the relative leaf area and the relative leaf cover of weeds. Weed Science, Lawrence, v.47, n.3, p.297-304, 1999.

SAS - Institute Statistical Analysis System. User's guide: version 6.4.ed. Cary : SAS Institute, 1989. 846p.

VITTA, J.I.; FERNANDEZ QUINTANILlA, C. Canopy measurements as predictors of weed-crop competition. Weed Science, Champaign, v.44, n.3, p.511-516, 1996.

VITTA, J.I.; SATORRE, E.H.; LEGUIZAMON, E.S. Using canopy attributes to evaluate competition between Sorghum halepense (L.) Pers. and soybean. Weed Research, Oxford, v.33, n.1, p.88-97, 1993. 